\title{
ALTERNATIVES TO THE TUBERCULIN SKIN TEST: INTERFERON- $\gamma$ ASSAYS IN THE DIAGNOSIS OF MYCOBACTERIUM TUBERCULOSIS INFECTION
}

\author{
M Pai
}

\begin{abstract}
For nearly a century, there were no alternatives to the tuberculin skin test (TST) for diagnosing latent tuberculosis infection. Because of advances in immunology and genomics, for the first time, an alternative has emerged in the form of $\mathrm{T}$ cell based interferon-g (IFN- $\gamma$ ) assays, a new generation of in vitro tests of cellular immunity. These assays measure cell mediated immune response by quantifying IFN- $\gamma$ released by $\mathrm{T}$ cells in response to stimulation by Mycobacterium tuberculosis antigens. Although early versions of IFN- $\gamma$ assays used purified protein derivative (PPD) as the stimulating antigen, newer versions use antigens that are significantly more specific to $M$. tuberculosis. These specific antigens include ESAT-6 and CFP-10. These proteins, encoded by genes located within the region of difference 1 (RD1) segment of the M. tuberculosis genome, are more specific to M. tuberculosis than PPD because they are not shared with any BCG substrains or several nontuberculous mycobacterial species. A review of current evidence on the performance of IFN- $\gamma$ assays and TST suggests that both the TST and IFN- $\gamma$ assays have advantages and limitations, and both tests appear to be useful at this time. The emergence of IFN- $\gamma$ assays is a much anticipated, welcome development that has, for the first time, increased the choice of tests available for diagnosing latent tuberculosis infection. Because both tests have their strengths and limitations, the decision to select one over the other will depend on the population, the goal of testing, and the resources available. To fully evaluate the utility of IFN- $\gamma$ assays in high burden countries such as India, long-term cohort studies are needed to determine the association between positive IFN- $\gamma$ results and the subsequent risk of active disease.
\end{abstract}

Key words: Tuberculosis, interferon-gamma assays, tuberculin skin test, diagnostic accuracy

The World Health Organization estimates that one third of the world's population is infected with Mycobacterium tuberculosis. ${ }^{1}$ This enormous reservoir of infected individuals presents a major hurdle for global tuberculosis (TB) control. In low TB endemic countries, targeted testing for latent tuberculosis infection (LTBI) and treatment is a key part of the TB control strategy. In high burden countries such as India, diagnosis and treatment of active tuberculosis receives greater priority; testing for LTBI is usually done only in selected high risk groups such as children, household contacts, and individuals with Human Immunodeficiency Virus (HIV) infection. How is LTBI diagnosed and what are the diagnostic options available?

\section{The need for alternatives to the tuberculin skin test}

The tuberculin skin test (TST) was, until recently, the only test available for the diagnosis of LTBI. ${ }^{2-7}$ The TST measures delayed type hypersensitivity response to the purified protein derivative (PPD). A major limitation of PPD is the fact that

*Corresponding author (email: <madhupai@berkeley.edu>) Division of Epidemiology, University of California, Berkeley, CA 94720, and Division of Pulmonary \& Critical Care Medicine, San Francisco General Hospital, University of California, San Francisco, USA.

Received: 16-11-2004

Accepted: 22-03-2005 it is a crude mixture of several antigens, many of which are shared among M. tuberculosis, M. bovis BCG, and several non-tuberculous mycobacteria (NTM). As a result, a positive TST result could potentially be due to true infection with $M$. tuberculosis, prior BCG vaccination, or due to exposure to NTM. ${ }^{2,5-8}$ Separating these components of the tuberculin response is not easy and is partly the basis for using risk stratified cut points in different population subgroups. ${ }^{8}$ It is well known that the TST has lower specificity in populations with high BCG coverage and NTM exposure..$^{2-7,9}$ Also, its sensitivity may be low due to anergy in individuals with depressed immunity (e.g. HIV infection). ${ }^{2-7,9}$ Further, the administration and reading of TST poses several unique problems - under reading, within and between reader variability, digit preference, the need for trained personnel to read the test results, and the requirement for patients to return for the purpose test reading. On account of all these limitations, there has always been a need to develop alternative tests for latent TB infection. Strangely, despite these limitations, for a long time little research went into the development of alternative tests for latent TB. This neglect is also noticeable in the persistent lack of new vaccines and drugs for tuberculosis.

\section{Development and evolution of interferon- $\gamma$ assays}

The successful sequencing of M. tuberculosis and M. bovis genomes has lead to the emergence of the field of comparative 
genomics (i.e., analysis and comparison of genomes from different species). Recent advances in genomics, molecular biology, and immunology have led to a promising generation of alternative tests such as $\mathrm{T}$ cell based, in vitro, interferon- $\gamma$ (IFN- $\gamma$ ) assays. ${ }^{9-12}$ The IFN- $\gamma$ assay is based on the concept that $\mathrm{T}$ cells of individuals sensitized with $M$. tuberculosis release interferon- $\gamma$ (IFN- $\gamma$ ), a Th-1 cytokine, when they reencounter mycobacterial antigens (Figure 1).

This process, unlike the TST, occurs ex vivo. A high level of IFN- $\gamma$ response is likely to indicate previous sensitization with $M$. tuberculosis, but does not necessarily imply active disease. In this respect, the IFN- $\gamma$ assay is similar to the TST. It cannot easily distinguish between latent infection and active disease.

While early versions of IFN- $\gamma$ assays employed PPD as the stimulating antigen, it became clear that such assays will have the same specificity problems seen with the PPD based TST. ${ }^{12}$ Extensive basic science research lead to the development of newer assays that employ antigens that are highly specific to $M$. tuberculosis. These antigens include the early secretory antigenic target 6 (ESAT-6) and culture filtrate protein (CFP-10). These low molecular weight proteins, encoded within the region of difference 1 (RD1) of the $M$. tuberculosis genome, are more specific to $M$. tuberculosis than PPD, and they are not shared with the BCG sub strains and most NTM species (with the exception of M. kansasii, $M$. marinum and M. szulgai). ${ }^{9-11}$ Tests based on these TB specific antigens are called RD1 based IFN- $\gamma$ assays. With the introduction of RD1 based assays, PPD based IFN- $\gamma$ assays are already being phased out.

Two RD1 based IFN- $\gamma$ assays are now available commercially. The QuantiFERON-TB ${ }^{\circledR}$ assay (Cellestis Limited, Carnegie, Australia) was the first IFN- $\gamma$ assay to become commercially available. This whole blood test was approved by the US Food and Drug Administration (FDA) in 2001 and is available in many countries. ${ }^{13}$ However, this first generation assay measures IFN- $\gamma$ response to PPD and thus is susceptible to the same specificity problems as the TST. ${ }^{9}$ This PPD based assay is currently being replaced by

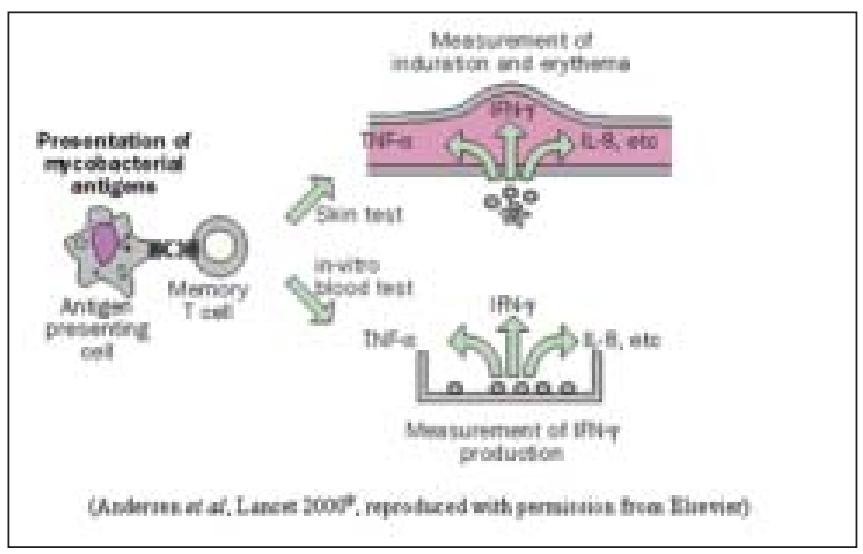

Figure 1: Biological basis of cellular immune based tests ${ }^{9}$ an enhanced assay, the QuantiFERON-TB-Gold ${ }^{\circledR}$ test (which uses ESAT-6 and CFP-10 in place of PPD). This new assay is currently available in Europe, and was approved by the US FDA in December 2004.

Other assays, including those using the enzyme linked immunospot (ELISPOT) to detect IFN- $\gamma$ response, have also been evaluated in different settings. ${ }^{9,11,12}$ The T SPOT-TB ${ }^{\circledR}$ (Oxford Immunotec, Oxon, UK) is the second assay to reach commercial development. This assay, performed using peripheral blood mononuclear cells (PBMC), employs ESAT6 and CFP-10, and detects the number of IFN- $\gamma$ producing $\mathrm{T}$ cells using a sensitive ELISPOT technology. This test, currently available in Europe, is awaiting US FDA approval. In India, both QuantiFERON-TB Gold and T SPOT-TB assays have been evaluated in research settings, in rural ${ }^{14}$ and urban populations. ${ }^{15}$ However, these assays are currently not used in clinical practice in India.

\section{Laboratory characteristics of IFN- $\gamma$ assays}

Although all IFN- $\gamma$ assays are cellular immune based tests that quantify IFN- $\gamma$ response, the operational and laboratory characteristics of these assays are quite variable (Figure 2). ${ }^{12}$

The QuantiFERON-TB-Gold and T SPOT-TB, the two commercially available RD1-based tests, are quite different

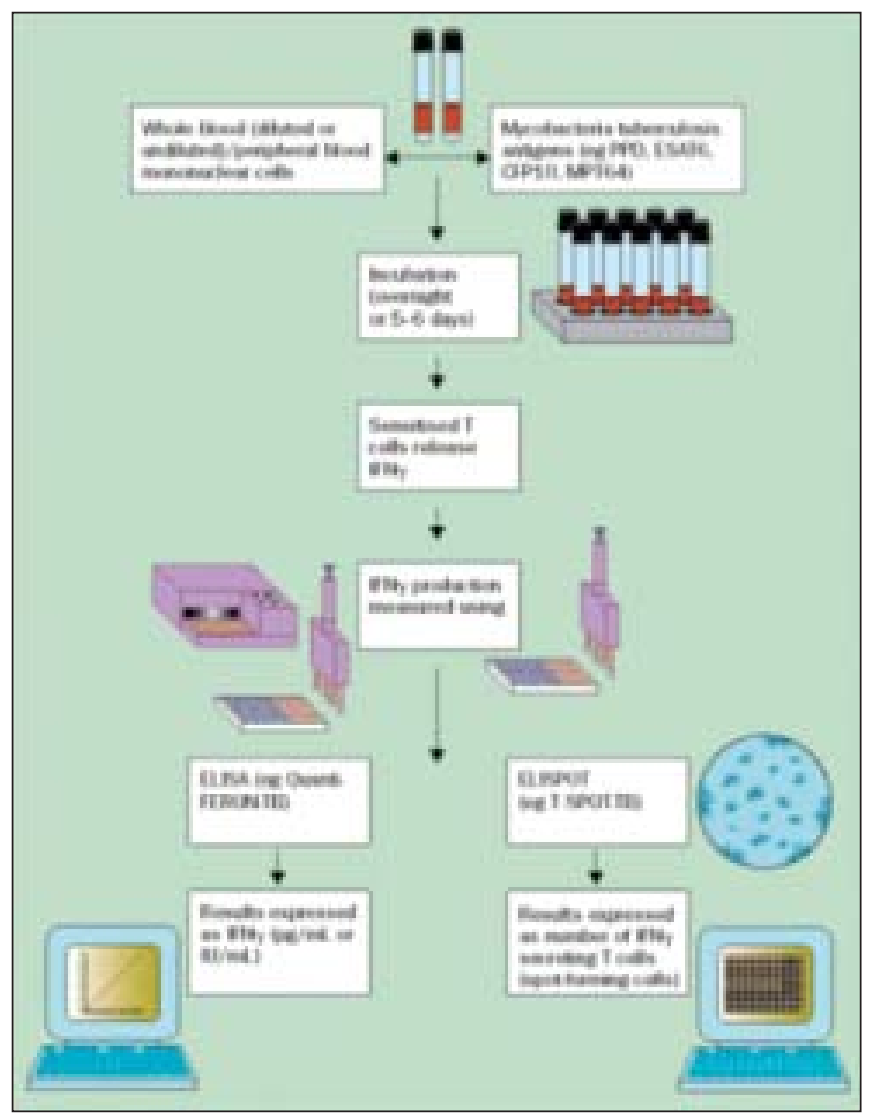

Figure 2: Laboratory aspects of interferon-gamma assay technology (ref $12)$; reproduced with permission from Elsevier 
in their assay formats and laboratory procedures (Figure 3 and 4). The incubation periods used in assays vary from short (16 - 24 hours in QuantiFERON-TB, and T SPOT-TB) to long ( 5 - 6 days in several in-house assays). Some assays use whole blood (QuantiFERON-TB), while others use PBMC (T SPOT-TB). The antigens used is PPD in some assays (first generation QuantiFERON-TB), while they are RD1 based in others (QuantiFERON-TB Gold, T SPOT-TB). While most

\section{Stage One - Blood Incubation and Harvesting}

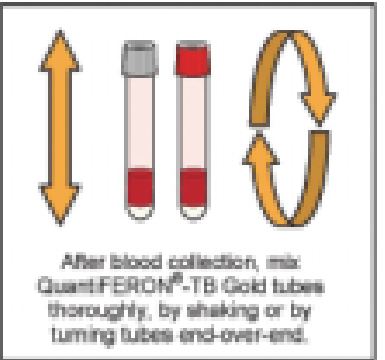

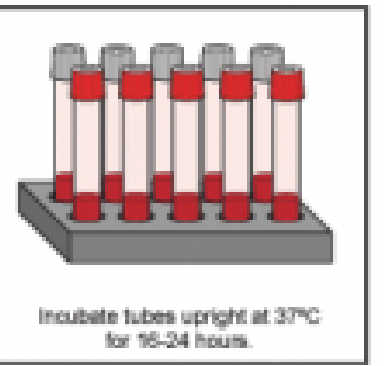
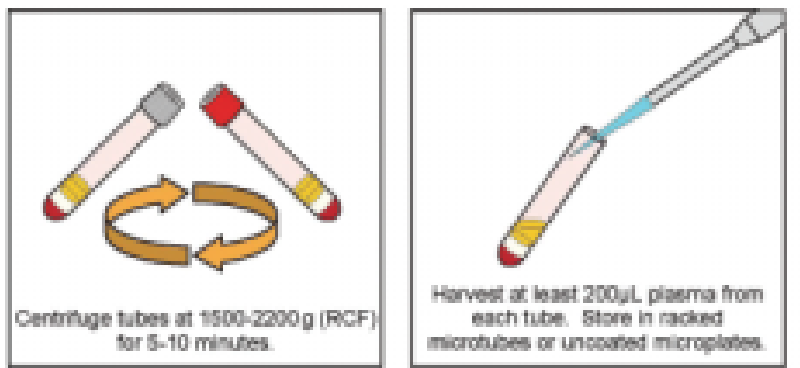

\section{Stage Two - Human IFN- $\gamma$ ELISA}
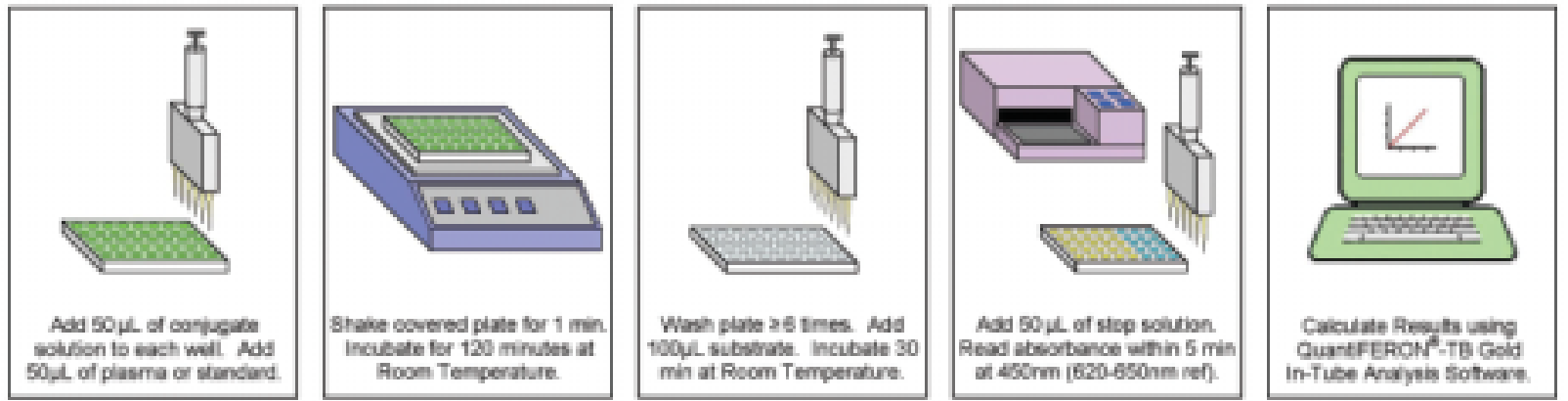

Figure 3: Overview of the QuantiFERON-TB Gold® in tube assay technology reproduced with permission (www.cellestis.com)

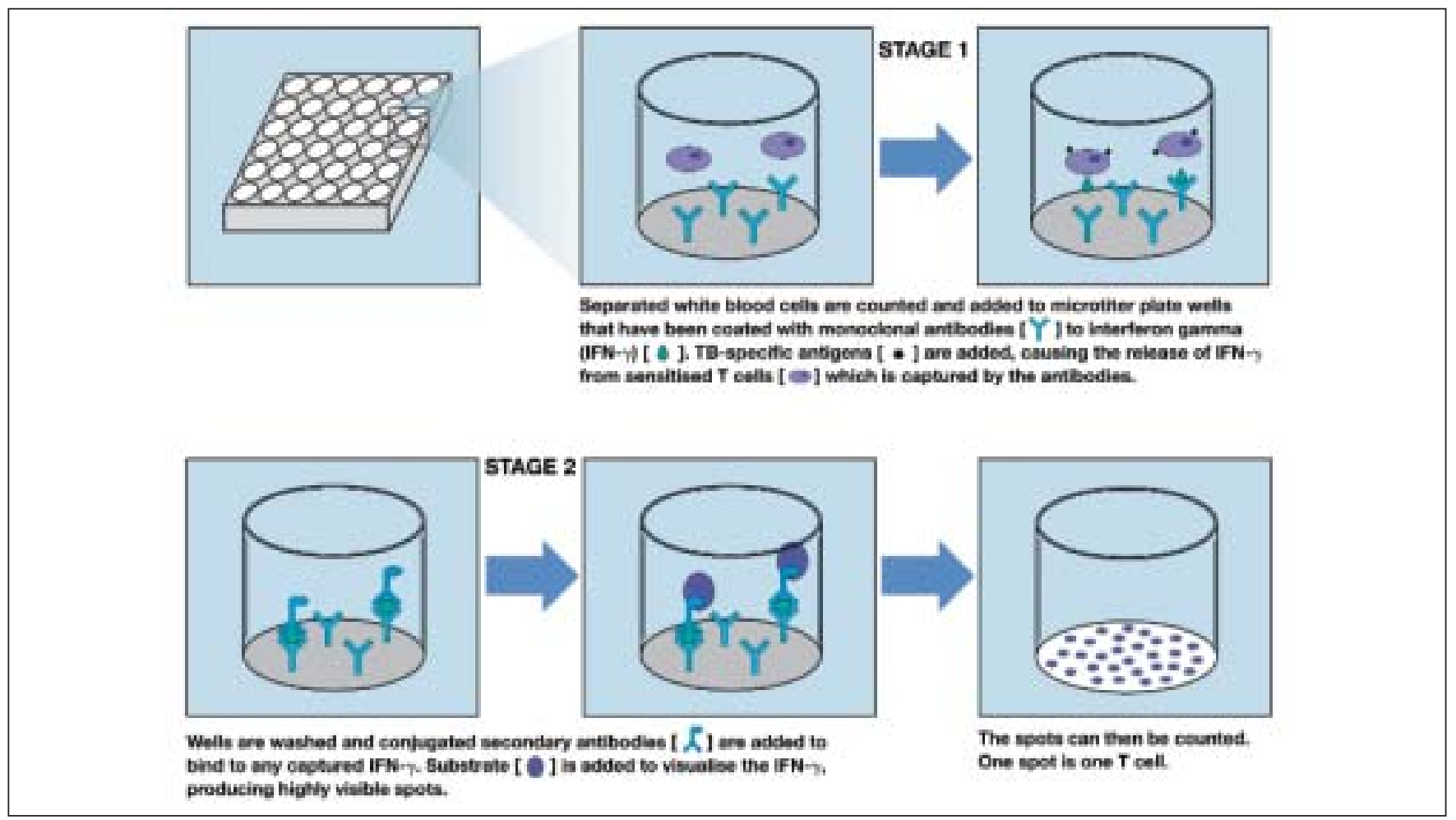

Figure 4: Overview of the T SPOT-TB $®$ assay technology reproduced with permission (www.oxfordimmunotec.com) 
assays use the ELISA format (QuantiFERON-TB), some use the ELISPOT format (T SPOT-TB) for IFN- $\gamma$ measurement. Assays also vary in the source and type of antigens used for stimulation - some use antigens whereas others use peptides (recombinant rESAT-6 peptides).

It is not clear at this time whether some assay characteristics are likely to increase test accuracy. For example, it is not clear whether assays that use longer incubation periods are likely to have higher sensitivity. Overnight incubation assays primarily detect immediate effector $\mathrm{T}$ cells that have already been activated in vivo, whereas in the longer incubation periods used in other assays, there is sufficient time in which to activate resting memory T cells as well. Similarly, there are no studies on whether the
ELISPOT format is more or less sensitive than the ELISA method. It does appear that adding specific antigens and using them as "cocktails" or antigenic mixtures does increase sensitivity, without sacrificing specificity. ${ }^{12}$ The technology of IFN- $\gamma$ assays is constantly evolving, and much effort is being directed toward the development of better TB specific antigens that can be used for both diagnostic purposes and the design of new vaccines. ${ }^{9}$

\section{Comparison of IFN- $\gamma$ assays with tuberculin skin testing}

Table 1 presents a comparison of the performance and operational characteristics of IFN- $\gamma$ assays with the tuberculin skin test, based on the available, published evidence (extensively reviewed elsewhere ${ }^{9,12}$ ). It must be kept in mind

\section{Table 1: Summary of evidence on the performance and operational characteristics of TST and RD1-based IFN- $\gamma$ assays*}

Performance and operational characteristics $\quad$ Tuberculin skin test (TST)

Estimated sensitivity (in patients with active TB)

Estimated specificity (in healthy individuals with no known TB disease/exposure)

Cross-reactivity with BCG

Cross-reactivity with non-tuberculous mycobacteria (NTM)

Association between test-positivity and subsequent risk of active TB during follow-up

Correlation with M. tuberculosis exposure

Benefits of treating test-positives (based on randomized controlled trials) Reliability (reproducibility)

Boosting phenomenon

Adverse reactions

Material costs

Patient visits

Laboratory infrastructure required

Time to obtain a result

Trained personnel required
Moderate to strong positive association (risk ratios [largest vs. smallest TST reactors] vary widely from 2.2 to 26.3$)^{2,6,17,18}$ Yes $^{44-46}$

$75 \%-90 \%{ }^{2-4,6,8,16,26}$ (lower in immunocompromised populations)

$70 \%-95 \%$ 2-4,6,8,16,26

Yes $^{5-7,37,38}$

$\mathrm{Yes}^{2,4-6}$

About $60 \%$ reduction of active TB among those treated compared to placebo ${ }^{6,8,16,19}$ Moderate (potential for digit preference, inter-reader variability, and under -reading $)^{2,5,6,48}$

Yes, can occur with repeated testing ${ }^{2,4,6,51}$ Rare (blistering and ulceration can occur in $1-2 \%$ of those with positive reactions) ${ }^{6}$ Low

Two

No

$2-3$ days

Yes (e.g. health workers, nurses, physicians)
RD1-based IFN- $\gamma$ assay

$80 \%-90 \%{ }^{15,27-33}$ (inadequate data in immunocompromised populations

$95 \%-100 \%^{27-32,34-36}$

Less likely ${ }^{39-42}$

Less likely (but can still cross-react with some species of NTM) ${ }^{43}$

Inadequate evidence, but one small study showed a strong association (risk ratio 10$)^{22}$ Yes (correlated better with exposure than TST in some, but not all, head-to-head comparisons) ${ }^{39-41,47,52}$

No evidence

Limited evidence but appears high $^{49,50}$ (digit preference not possible; unknown reproducibility in the same individual; inter-laboratory variability not well studied)

No

Rare (risks are mainly related to venipuncture)

Moderate to high

One

Yes

$1-2$ days, but may be longer if run as batches

Yes (e.g. laboratory technicians)

*Superscripts indicate references 
that this summary of evidence is likely to change as new studies on IFN- $\gamma$ assays are constantly advancing the state of the art. As seen in Table 1, the TST has moderate to high, but variable sensitivity and specificity, depending on the population screened. ${ }^{2,4-6,16}$ Specificity of TST tends to vary more than sensitivity. Several longitudinal studies, including a large study from India, ${ }^{17}$ have shown a positive association between TST response and subsequent risk of active TB., 2,6,17,18 Therefore, although crude and imprecise, the TST has the ability to predict active TB among latently infected individuals. Several randomized trials have shown that treatment of LTBI, diagnosed on the basis of positive TST, reduces the risk of active $\mathrm{TB}$ by about $60 \%$. $^{6,8,16,19}$ This experimental evidence, in fact, has lead to the policy of targeted tuberculin testing and LTBI treatment (e.g. isoniazid for $6-9$ months) in developed countries. ${ }^{8}$

Further, the TST is a simple test with low material costs that does not require a laboratory. It has, therefore, been extensively used even in resource limited settings for both clinical testing (in children) and epidemiological field studies. ${ }^{5,7}$ In India, several studies on annual risk of TB infection (ARI) have been conducted using TST. ${ }^{5,20}$

Research evidence suggests that RD1 based IFN- $\gamma$ assays outperform the TST with respect to the following characteristics: higher specificity, better correlation with indirect measures of exposure to $M$. tuberculosis, and relatively less cross reactivity due to $\mathrm{BCG}$ vaccination and NTM infection. ${ }^{9-13,21}$ In terms of sensitivity, RD1 based IFN- $\gamma$ assays that use cocktails of specific antigens (a mixture of ESAT-6 and CFP-10) appear to be at least as sensitive as the PPD based TST. ${ }^{12}$ The other advantages include rapidity, the need for only a single patient visit, avoidance of subjective and poorly reliable measurements such as skin induration, and the ability to perform repeat testing without boosting. There is limited evidence, based on one small study, of an association between IFN- $\gamma$ response to ESAT- 6 and subsequent progression to active TB among contacts of TB patients. ${ }^{22}$ To date, no clinical trial has demonstrated the efficacy of treatment on the basis of IFN- $\gamma$ assay results. In other words, we do not know if treatment of individuals positive by the IFN- $\gamma$ assay will prevent the development of active disease in future. A major limitation of IFN- $\gamma$ assays is their higher material costs and the need for laboratory infrastructure (the laboratory has to have the capacity to run ELISA or ELISPOT) ${ }^{12}$ In India, although no formal costing studies have been conducted, the material cost of IFN- $\gamma$ assays may be 5 - 10 times higher than TST. This cost differential might be less striking in other settings (USA) where labor costs are significantly higher, making the TST, as a whole, an expensive test. $^{23}$

Because of the lack of a gold standard for latent infection, it is impossible to accurately determine the sensitivity and specificity of IFN- $\gamma$ assays for the diagnosis of latent infection.
Therefore, several studies have evaluated the agreement (concordance) between TST and IFN- $\gamma$ assays (Table 2).

This approach avoids the use of TST, an imperfect test, as the gold standard. Most studies reported modest to high agreement $(60 \%$ to $80 \%)$ between the two tests. The only Indian study to evaluate the agreement between TST and an IFN- $\gamma$ assay reported a high degree of agreement of $81 \% .^{14}$ This study of 726 health care workers, conducted in a rural hospital in Sevagram, Maharashtra, compared the third generation QuantiFERON-TB Gold In Tube assay (RD1 based) with TST (1 TU dose of PPD RT23). This large study also showed that previous BCG vaccination had little impact on both TST and QuantiFERON-TB Gold results in adult health care workers.

\section{Conclusions}

Current evidence suggests that both the TST and IFN- $\gamma$ assays have advantages and limitations, and both tests appear to be useful. No single test, at this time, might suit all conditions. The emergence of IFN- $\gamma$ assays is a much anticipated development that has, for the first time, increased the diagnostic tools available for LTBI. It is, therefore, important to consider both tests as part of an expanding armamentarium of TB diagnostics. In this context, the decision to select one or the other will depend on the population, the goal of testing, and the resources available. For example, serial monitoring of health care workers (annual testing) is a key component of nosocomial TB control in many developed countries. In such settings, the RD1 based IFN- $\gamma$ assay might be a more appropriate test. It will eliminate the need for repeat visits and two step TST testing, avoid boosting, and minimize interpretational difficulties. Because of its higher specificity, IFN- $\gamma$ assays will be helpful in low endemic populations where cross reactivity due to BCG and NTM pose problems in TST interpretation. It is also likely to reduce false positives and enhance targeted LTBI treatment, particularly in low incidence settings. Cross reactivity due to BCG appears to be an important issue in some populations where BCG vaccination is not given at birth, but later on in life. Further, IFN- $\gamma$ assays may be helpful in screening populations such as HIV-infected individuals, homeless individuals, and injection drug users, where low return rates for TST reading is a major concern.

In high-burden and resource-limited settings such as India, where even access to simple technology such as sputum microscopy may be poor in some areas, the TST might continue to serve a useful purpose. In the Indian context, a 15 year follow up of 280,000 subjects from the south Indian BCG vaccine trial has showed that TST response is significantly associated with development of active TB. ${ }^{17}$ This study and other Indian studies suggest that the TST remains a useful test. ${ }^{5,17,20}$ Also, data from several studies in India suggest that BCG vaccination may not pose a major problem 
Table 2: Summary of studies on agreement between RD1-based IFN- $\gamma$ assays and tuberculin skin testing

\begin{tabular}{|c|c|c|c|c|}
\hline Study & Study population & $\begin{array}{l}\text { IFN- } \gamma \text { (antigen, } \\
\text { format) }\end{array}$ & $\begin{array}{l}\text { TST (technique, } \\
\text { dose, cut-point) }\end{array}$ & Agreement (kappa) \\
\hline USA, $1999^{34}$ & $\begin{array}{l}43 \text { participants ( } 27 \text { active TB, } 8 \mathrm{M} \text {. } \\
\text { avium disease, } 8 \text { healthy controls) }\end{array}$ & ESAT-6 (In-house) & $\begin{array}{l}\text { Mantoux, 5TU } \\
\text { PPD-S (5 mm) }\end{array}$ & $74 \%(0.52)$ \\
\hline Netherlands, $2001^{49}$ & $\begin{array}{l}44 \text { contacts of a case of smear } \\
\text {-positive TB }\end{array}$ & $\begin{array}{l}\text { ESAT-6, CFP-10 } \\
\text { (In-house) }\end{array}$ & $\begin{array}{l}\text { Mantoux, 2TU } \\
\text { RT23 (10 mm) }\end{array}$ & $89 \%(0.73)$ \\
\hline $\mathrm{UK}, 2001^{41}$ & $\begin{array}{l}50 \text { healthy adult contacts of } \\
\text { patients with smear-positive TB }\end{array}$ & ESAT-6 (ELISPOT) & $\begin{array}{l}\text { Heaf test (grades } \\
3 \& 4)\end{array}$ & $69 \%(0.37)$ \\
\hline Zambia, $2002^{30}$ & $\begin{array}{l}49 \text { healthy adults (14 HIV-positive) } \\
\text { with no history of TB }\end{array}$ & $\begin{array}{l}\text { ESAT-6, CFP-10 } \\
\text { (ELISPOT) }\end{array}$ & $\begin{array}{l}\text { Mantoux,5TU } \\
\text { PPD RT23 } \\
(10 \mathrm{~mm})\end{array}$ & $\begin{array}{l}\text { HIV-: } 60 \%(0.03) \\
\text { HIV+: } 64 \%(0.26)\end{array}$ \\
\hline $\mathrm{UK}, 2003^{40}$ & $\begin{array}{l}535 \text { students screened in a school } \\
\text { outbreak }\end{array}$ & $\begin{array}{l}\text { ESAT-6, CFP-10 } \\
\text { (ELISPOT) }\end{array}$ & $\begin{array}{l}\text { Heaf test (grades } \\
3 \text { and } 4 \text {, irrespective } \\
\text { of BCG; grade } 2 \\
\text { among unvaccinated) }\end{array}$ & $89 \%(0.72)$ \\
\hline Italy, $2004^{47}$ & $\begin{array}{l}92 \text { contacts of an index case of } \\
\text { drug resistant } \mathrm{TB}\end{array}$ & $\begin{array}{l}\text { ESAT-6, CFP-10 } \\
\text { (ELISPOT) }\end{array}$ & $\begin{array}{l}\text { Mantoux, 5TU PPD- } \\
\mathrm{S}(5 \mathrm{~mm})\end{array}$ & $82 \%(0.13)$ \\
\hline Gambia, $2004^{52}$ & $\begin{array}{l}735 \text { household contacts of } \\
\text { smear-positive TB patients }\end{array}$ & $\begin{array}{l}\text { ESAT-6, CFP-10 } \\
\text { (ELISPOT) }\end{array}$ & $\begin{array}{l}\text { Mantoux, 2TU RT23 } \\
(10 \mathrm{~mm})\end{array}$ & $74 \%(0.43)$ \\
\hline Denmark, $2004^{39}$ & $\begin{array}{l}85 \text { BCG-unvaccinated contacts } \\
\text { of an index TB case in a school }\end{array}$ & $\begin{array}{l}\text { ESAT-6, CFP-10 } \\
\text { (QuantiFERON-TB } \\
\text { Gold) }\end{array}$ & $\begin{array}{l}\text { Mantoux, 2TU RT23 } \\
(10 \mathrm{~mm})\end{array}$ & $94 \%(0.87)$ \\
\hline India, $2005^{14}$ & $\begin{array}{l}726 \text { health care workers in a rural } \\
\text { hospital }\end{array}$ & $\begin{array}{l}\text { ESAT-6, CFP-10, } \\
\text { TB7.7(QuantiFERON } \\
\text {-TB Gold In Tube) }\end{array}$ & $\begin{array}{l}\text { Mantoux, 1TU RT23 } \\
(10 \mathrm{~mm})\end{array}$ & $81 \%(0.61)$ \\
\hline
\end{tabular}

*Superscripts indicate references

in the interpretation of TST results. ${ }^{14,24,25}$ Recent nationwide tuberculin surveys in India, involving more than 100,000 children, have also shown the BCG does not substantially affect the estimation of annual risk of infection. ${ }^{24,25}$ However, BCG might adversely affect TST results in other populations, depending on BCG strain used, timing of vaccination, frequency, and time elapsed since vaccination. ${ }^{38}$ It is therefore important to consider these issues carefully before selecting the appropriate test.

To fully evaluate the utility of IFN- $\gamma$ assays in high burden countries such as India, long term cohort studies are needed to determine the association between positive IFN- $\gamma$ results and the subsequent risk of active TB. If these studies consistently demonstrate a strong association between positive IFN- $\gamma$ results and risk of active TB, and if the effect is stronger than that of TST, this would indicate that IFN- $\gamma$ assays have a better ability to identify those at higher risk for progressing to active disease. It is also important to determine if treatment of individuals diagnosed to have LTBI using IFN- $\gamma$ assay will result in protection against development of active tuberculosis. These studies should help to settle the debate on whether IFN$\mathrm{g}$ assays can replace the TST. For now, it is probably a good strategy to keep both TST and IFN- $\gamma$ assays on the LTBI diagnostic menu, and select the appropriate test based on the population, the purpose of testing, and the resources available.

\section{Acknowledgements}

This work was supported by the Fogarty AIDS International Training Program (1-D43-TW00003-16), and NIH/NIAID (R01 AI 34238). This article is partly based on a previously published systematic review on IFN- $\gamma$ assays (Pai M, et al. Lancet Infect Dis 2004;4:76176). The author is grateful to SP Kalantri, P Narang, DK Mendiratta, R Joshi, and S Dogra, from the Mahatma Gandhi Institute of Medical Sciences, Sevagram, for their support with collaborative research projects.

\section{References}

1. Dye C, Scheele S, Dolin P, Pathania V, Raviglione MC. Consensus statement. Global burden of tuberculosis: estimated incidence, prevalence, and mortality by country. WHO Global Surveillance and Monitoring Project. JAMA 1999;282:677-86.

2. Huebner RE, Schein MF, Bass JB, Jr. The tuberculin skin test. Clin Infect Dis 1993;17:968-75.

3. Lee E, Holzman RS. Evolution and current use of the tuberculin test. Clin Infect Dis 2002;34:365-70.

4. Bass JB, Jr. The tuberculin skin test. In: Field MJ, edn. Tuberculosis in the workplace. Washington, D.C.: National Academy Press; 2001. p. 179-88.

5. Chadha VK. Tuberculin test. Indian J Pediatr 2001;68:53-8. 
6. Menzies RI. Tuberculin skin testing. In:Tuberculosis: a comprehensive international approach. Reichman LB, Hershfield ES, editors. New York: Marcel Dekker; 2000. p. 279322.

7. Rieder HL. Epidemiologic basis of tuberculosis control. Paris: International Union Against Tuberculosis and Lung Disease, 1999.

8. American Thoracic Society. Targeted tuberculin testing and treatment of latent tuberculosis infection. Am J Respir Crit Care Med 2000;161:221-47.

9. Andersen P, Munk ME, Pollock JM, Doherty TM. Specific immune-based diagnosis of tuberculosis. Lancet 2000;356:1099104.

10. Barnes PF. Diagnosing latent tuberculosis infection: turning glitter to gold. Am J Respir Crit Care Med 2004;170:5-6.

11. Lalvani A. Spotting latent infection: the path to better tuberculosis control. Thorax 2003;58:916-8.

12. Pai M, Riley LW, Colford JM. Interferon-g assays in the immunodiagnosis of tuberculosis: a systematic review. Lancet Infect Dis 2004;4:761-76.

13. Mazurek GH, Villarino ME. Guidelines for using the QuantiFERON-TB test for diagnosing latent Mycobacterium tuberculosis infection. Centers for Disease Control and Prevention. MMWR Recomm Rep 2003;52:15-8.

14. Pai M, Gokhale K, Joshi R, Dogra S, Kalantri SP, Mendiratta $\mathrm{DK}$, et al. Mycobacterium tuberculosis infection in health care workers in rural India: comparison of a whole-blood, interferong assay with tuberculin skin testing. JAMA 2005;293:2746-55.

15. Lalvani A, Nagvenkar P, Udwadia Z, Pathan AA, Wilkinson KA, Shastri JS, et al. Enumeration of T cells specific for RD1encoded antigens suggests a high prevalence of latent Mycobacterium tuberculosis infection in healthy urban Indians. J Infect Dis 2001;183:469-77.

16. Jasmer RM, Nahid P, Hopewell PC. Clinical practice. Latent tuberculosis infection. N Engl J Med 2002;347:1860-6.

17. Radhakrishna S, Frieden TR, Subramani R. Association of initial tuberculin sensitivity, age and sex with the incidence of tuberculosis in south India: a 15-year follow-up. Int J Tuberc Lung Dis 2003;7:1083-91.

18. Watkins RE, Brennan R, Plant AJ. Tuberculin reactivity and the risk of tuberculosis: a review. Int J Tuberc Lung Dis 2000;4:895903.

19. Comstock GW. How much isoniazid is needed for prevention of tuberculosis among immunocompetent adults? Int J Tuberc Lung Dis 1999;3:847-50.

20. Chadha VK. Epidemiological situation of tuberculosis in India. J Indian Med Assoc 2003;101:144-7.

21. Lein AD, Von Reyn CF. In vitro cellular and cytokine responses to mycobacterial antigens: Application to diagnosis of tuberculosis infection and assessment of response to mycobacterial vaccines. American Journal of the Medical Sciences 1997;313:364-71.

22. Doherty TM, Demissie A, Olobo J, Wolday D, Britton S, Eguale $\mathrm{T}$, et al. Immune responses to the Mycobacterium tuberculosisspecific antigen ESAT-6 signal subclinical infection among contacts of tuberculosis patients. J Clin Microbiol 2002;40:704-6.

23. Lambert L, Rajbhandary S, Quails N, Budnick L, Catanzaro A, Cook S, et al. Costs of implementing and maintaining a tuberculin skin test program in hospitals and health departments. Infect Control Hosp Epidemiol 2003;24:814-20.

24. Chadha VK, Jaganath PS, Kumar P. Tuberculin sensitivity among children vaccinated with BCG under universal immunization programme. Indian J Pediatr 2004;71:1063-8.

25. Chadha VK, Jagannatha PS, Kumar P. Can BCG-vaccinated children be included in tuberculin surveys to estimate the annual risk of tuberculous infection in India? Int $J$ Tuberc Lung Dis 2004;8:1437-42.

26. American Thoracic Society. Diagnostic Standards and Classification of Tuberculosis in Adults and Children. Am J Respir Crit Care Med 2000;161:1376-95.

27. Arend SM, Andersen P, van Meijgaarden KE, Skjot RL, Subronto YW, van Dissel JT, et al. Detection of active tuberculosis infection by $\mathrm{T}$ cell responses to early-secreted antigenic target $6-\mathrm{kDa}$ protein and culture filtrate protein $10 . \mathrm{J}$ Infect Dis 2000;181:1850-4.

28. Brock I, Munk ME, Kok-Jensen A, Andersen P. Performance of whole blood IFN-gamma test for tuberculosis diagnosis based on PPD or the specific antigens ESAT-6 and CFP-10. Int $J$ Tuberc Lung Dis 2001;5:462-7.

29. Brock I, Weldingh K, Leyten EM, Arend SM, Ravn P, Andersen P. Specific T-cell epitopes for immunoassay-based diagnosis of Mycobacterium tuberculosis infection. J Clin Microbiol 2004;42:2379-87.

30. Chapman AL, Munkanta M, Wilkinson KA, Pathan AA, Ewer $\mathrm{K}$, Ayles $\mathrm{H}$, et al. Rapid detection of active and latent tuberculosis infection in HIV-positive individuals by enumeration of Mycobacterium tuberculosis-specific T cells. AIDS 2002;16:2285-93.

31. Lalvani A, Pathan AA, McShane H, Wilkinson RJ, Latif M, Conlon CP, et al. Rapid detection of Mycobacterium tuberculosis infection by enumeration of antigen-specific $\mathrm{T}$ cells. Am J Respir Crit Care Med 2001;163:824-8.

32. Mori T, Sakatani M, Yamagishi F, Takashima T, Kawabe Y, Nagao K, et al. Specific detection of tuberculosis infection: an interferon-gamma-based assay using new antigens. Am J Respir Crit Care Med 2004;170:59-64.

33. Liebeschuetz S, Bamber S, Ewer K, Deeks JJ, Pathan AA, Lalvani A. Diagnosis of tuberculosis in South African children with a $\mathrm{T}$ cell-based assay: a prospective cohort study. Lancet 2004. 
34. Lein AD, von Reyn CF, Ravn P, Horsburgh CR, Jr. Alexander LN, Andersen P. Cellular immune responses to ESAT-6 discriminate between patients with pulmonary disease due to Mycobacterium avium complex and those with pulmonary disease due to Mycobacterium tuberculosis. Clin Diagn Lab Immunol 1999;6:606-9.

35. Munk ME, Arend SM, Brock I, Ottenhoff TH, Andersen P. Use of ESAT-6 and CFP-10 antigens for diagnosis of extrapulmonary tuberculosis. J Infect Dis 2001;183:175-6.

36. Pathan AA, Wilkinson KA, Klenerman P, McShane H, Davidson RN, Pasvol G, et al. Direct ex vivo analysis of antigen-specific IFN-gamma-secreting CD4 $\mathrm{T}$ cells in Mycobacterium tuberculosis-infected individuals: associations with clinical disease state and effect of treatment. J Immunol 2001;167:521725 .

37. Menzies D. What does tuberculin reactivity after bacille CalmetteGuerin vaccination tell us? Clin Infect Dis 2000;31:71-4.

38. Wang L, Turner MO, Elwood RK, Schulzer M, FitzGerald JM. A meta-analysis of the effect of Bacille Calmette Guerin vaccination on tuberculin skin test measurements. Thorax 2002;57:804-9.

39. Brock I, Weldingh K, Lillebaek T, Follmann F, Andersen P. Comparison of tuberculin skin test and new specific blood test in tuberculosis contacts. Am J Respir Crit Care Med 2004; 170:65-9.

40. Ewer K, Deeks J, Alvarez L, Bryant G, Waller S, Andersen P, et al. Comparison of T-cell-based assay with tuberculin skin test for diagnosis of Mycobacterium tuberculosis infection in a school tuberculosis outbreak. Lancet 2003;361:1168-73.

41. Lalvani A, Pathan AA, Durkan H, Wilkinson KA, Whelan A, Deeks JJ, et al. Enhanced contact tracing and spatial tracking of Mycobacterium tuberculosis infection by enumeration of antigen-specific T cells. Lancet 2001;357:2017-21.

42. Mazurek GH, LoBue PA, Daley CL, Bernardo J, Lardizabal AA, Bishai WR, et al. Comparison of a whole-blood interferon gamma assay with tuberculin skin testing for detecting latent Mycobacterium tuberculosis infection. JAMA 2001;286:1740-7.

43. Arend SM, van Meijgaarden KE, de Boer K, de Palou EC, van
Soolingen D, Ottenhoff TH, et al. Tuberculin skin testing and in vitro T cell responses to ESAT-6 and culture filtrate protein 10 after infection with Mycobacterium marinum or M. kansasii. J Infect Dis 2002;186:1797-807.

44. Daniel TM. The occupational tuberculosis risk of health care workers. In: Field MJ, edn. Tuberculosis in the workplace. Washington, D.C.: National Academy Press; 2001. p. 189-229.

45. Menzies D, Fanning A, Yuan L, Fitzgerald M. Tuberculosis among health care workers. N Engl J Med 1995;332:92-8.

46. World Health Organization. Guidelines for the prevention of tuberculosis in health care facilities in resource-limited settings. Geneva: World Health Organization, 1999.

47. Richeldi L, Ewer K, Losi M, Bergamini BM, Roversi P, Deeks $\mathrm{J}$, et al. T cell-based tracking of multidrug resistant tuberculosis infection after brief exposure. Am J Respir Crit Care Med 2004;170:288-95.

48. Kendig EL, Jr. Kirkpatrick BV, Carter WH, Hill FA, Caldwell $\mathrm{K}$, Entwistle M. Underreading of the tuberculin skin test reaction. Chest 1998;113:1175-7.

49. Arend SM, Engelhard AC, Groot G, de Boer K, Andersen P, Ottenhoff TH, et al. Tuberculin skin testing compared with Tcell responses to Mycobacterium tuberculosis-specific and nonspecific antigens for detection of latent infection in persons with recent tuberculosis contact. Clin Diagn Lab Immunol 2001;8:1089-96.

50. Fietta A, Meloni F, Cascina A, Morosini M, Marena C, Troupioti $\mathrm{P}$, et al. Comparison of a whole-blood interferon-gamma assay and tuberculin skin testing in patients with active tuberculosis and individuals at high or low risk of Mycobacterium tuberculosis infection. Am J Infect Control 2003;31:347-53.

51. Menzies D. Interpretation of repeated tuberculin tests. Boosting, conversion, and reversion. Am J Respir Crit Care Med 1999;159:15-21.

52. Hill PC, Brookes RH, Fox A, Fielding K, Jeffries DJ, JacksonSillah D, et al. Large-scale evaluation of enzyme-linked immunospot assay and skin test for diagnosis of Mycobacterium tuberculosis infection against a gradient of exposure in The Gambia. Clin Infect Dis 2004;38:966-73. 